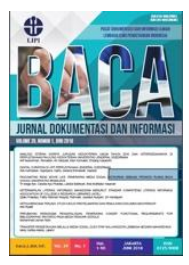

\title{
EVALUASI KUALITAS SISTEM JURNAL ELEKTRONIK BERBASIS OPEN JOURNAL SYSTEM MENGGUNAKAN ISO/IEC 25010
}

\author{
Deni Murdiani ${ }^{1 *}$; Rusydi Umar ${ }^{2}$ \\ ${ }^{1}$ Magister Universitas Ahmad Dahlan \\ ${ }^{2}$ Program Magister Teknik Informatika Universitas Ahmad Dahlan \\ *Korespondensi: denimurdiani@gail.com
}

Diajukan: 30-08-2019; Direview: 10-01-2020; Diterima: 18-02-2020; Direvisi: 08-03-2020

\begin{abstract}
This study aims to evaluate electronic journals based on the OJS used by MAARIF journals. Evaluation is carried out to see whether the system that has been designed is in accordance with the wishes of the user, and how much the level of satisfaction. Evaluation conducted in this study uses four characteristics that exist in ISO/IE 25010. As for the results, the usability characteristics test obtained as much as $76 \%$ respondents stated that the MAARIF Journal management system electronically was quite useful and satisfied for the manager and active reader of the MAARIF Journal. While testing functional suitability characteristics, the system meets the standards because the main function of the system built runs smoothly because it has an $\mathrm{X}$ value of close to 1 , which is 0.9 . In testing the performance efficiency characteristics have met the standard because the average time required to load the page for 3.7 seconds. The security characteristics test shows that MAARIF electronic journal management system has level 2 or medium level security.
\end{abstract}

\begin{abstract}
ABSTRAK
Penelitian ini bertujuan untuk mengevaluasi jurnal elektronik berbasis OJS yang digunakan oleh jurnal MAARIF. Evaluasi dilakukan untuk melihat apakah sistem yang telah dirancang sudah sesuai dengan keinginan pengguna, serta seberapa besar tingkat kepuasannya. Evaluasi yang dilakukan pada penelitian ini menggunakan empat karakteristik yang ada pada ISO/IE 25010. Hasil penelitian menunjukkan bahwa pengujian karakteristik usability terhadap $76 \%$ responden menyatakan bahwa sistem pengelolaan jurnal MAARIF secara elektronik cukup berguna dan puas bagi pengelola dan pembaca aktif Jurnal MAARIF. Sementara pada pengujian karakteristik functional suitability, sistem sudah memenuhi standar karena fungsi utama dari sistem yang dibangun berjalan dengan lancar karena memiliki nilai X mendekati 1 yaitu 0,9. Pada pengujian karakteristik performance efficiency telah memenuhi standar karena rata-rata waktu yang dibutuhkan untuk memuat halaman selama 3,7 detik. Pada pengujian karakteristik security diperoleh hasil bahwa sistem pengelolaan jurnal elektronik MAARIF memiliki tingkat keamanan level 2 atau medium.
\end{abstract}

Keywords: Journal; Open Journal System; ISO/IE 25010; Evaluation system

\section{PENDAHULUAN}

Salah satu cara untuk melihat kualitas sebuah sistem yang telah dibangun adalah dengan melakukan pengukuran dan memberikan penilaian. Pengukuran dan penilaian tersebut dapat dihasilkan melalui proses evaluasi kualitas sistem yang telah dirancang. Dari kegiatan evaluasi ini, kita dapat melihat melihat respon pengguna terhadap produk sistem yang telah dirancang (Nashihuddin \& Aulianto, 2015). Menurut Putra (2020), evaluasi merupakan proses identifikasi untuk mengukur/menilai apakah sebuah kegiatan atau program dilaksanakan sesuai perencanaan dan berhasil mencapai tujuan atau tidak. Evaluasi juga merupakan suatu kegiatan yang dilakukan dengan cara mengumpulkan data maupun informasi tentang bekerjanya suatu hal, kemudian hasilnya digunakan untuk menentukan alternatif dalam pengambilan keputusan secara efektif (Mirza, et al., 2019). Pada konteks sistem informasi, 
evalusi kualitas sebuah sistem dapat dilakukan dengan cara berbeda dan pada tingkatan berbeda, tergantung pada tujuan evaluasi, seperti untuk menilai kemampuan teknis suatu system, pelaksanaan oprasional, dan pendayagunaan sistem (Hakam, 2017).

Salah satu metode tolok ukur untuk mengevalusi kualitas sebuah sistem informasi dapat dilakukan dengan menggunakan standar ISO-25010 tentang System and Software Quality Requirment and Evaluation (Tangkudung et al., 2019). Standar tersebut untuk melihat kualitas sistem informasi dengan menggunakan dimensi product quality dan quality in uses sebagai dua dimensi umum (ISO 25000, 2011). ISO 25010 telah menjadi standar tolok ukur untuk menganalisis sistem informasi yang dikembangkan oleh perusahaan, instansi, dan organisasi. Melalui standar ini, evaluasi kualitas sistem informasi dapat dilakukan secara spesifik berdasarkan delapan karakter pada dimensi product quality, yaitu functional suitability, performance efficiency, compatibility, usability, reliability, security, maintainability, dan portability (ISO 25000, 2011).

Pada penelitian ini, penulis membahas tentang evalusi kualitas sistem jurnal elektronik MAARIF berbasis Open Journal System (OJS) menggunakan ISO 25010. Hal yang mendasari kajian ini adalah berdasarkan Permendiknas No.22 tahun 2011 tentang Terbitan Berkala Ilmiah, dalam Pasal 8.f, disebutkan bahwa terbitan berkala ilmiah dapat terakreditasi apabila diterbitkan secara tercetak dan secara elektronik melalui jejaring informasi dan komunikasi. Kemudian menindaklanjuti Peraturan Dirjen DIKTI No.49/Kep/2011 tentang Pedoman Akreditasi Terbitan Berkala Ilmiah, salah satu syarat utama pengajuan akreditasi jurnal ilmiah harus memiliki sistem pengelolaan jurnal secara elektronik (Lukman, 2015). Sejak 2019, Jurnal MAARIF telah mengembangkan pengelolaan jurnal ektronik dengan OJS, untuk meningkatkan kualitas manajemen penerbitan jurnal berdasarkan standar penerbitan jurnal ilmiah yang di tetapkan oleh Kemenristekdikti.

OJS adalah salah satu sistem manajemen konten berbasis web untuk pengelolaan keseluruhan proses manajemen publikasi jurnal ilmiah secara elektronik. OJS didistribusikan secara open source di bawah Public Knowlegde Project/PKP (Handoko, Arief, \& Yuhefizar, 2015). OJS merupakan sistem terbuka yang tersedia gratis untuk siapapun, maka semangat inilah yang diharapkan ditiru oleh para pengelola jurnal untuk menyediakan sumber terbuka terhadap informasi ilmiah yang dikelolanya dan diharapkan akan berdampak pada akselerasi atau percepatan desiminasi karya ilmiah (Prasetyawan, 2017).

Salah satu keunggulan OJS adalah telah teritegrasi dengan mesin pencari seperti Google dan Google Scholar, sehingga jurnal yang dikelola dengan OJS dapat dengan mudah terindeks oleh Google (Arief \& Handoko, 2016). OJS juga memudahkan peran pengelola jurnal, editor, reviewer, penulis, dan pembaca (Yuliana, 2018). Di Indonesia, penggunaan OJS sebagai sistem pengelolaan jurnal elektronik cukup seragam di berbagai perguruan tinggi dan juga lembaga pengelola jurnal. Hal ini mendorong para pengelola jurnal untuk belajar bersama tentang pengelolaan jurnal elektronik yang sesuai dengan standar nasional dan internasional. Penelitian ini membahas tentang empat tahapan pengujian dan evaluasi sistem pengelolaan jurnal elektronik berbasis OJS dari delapan karakteristik sesuai dengan ISO, yaitu: usability, functional suitability, performance efficiency, dan security.

\section{TINJAUAN PUSTAKA}

\subsection{Jurnal Elektronik}

Perkembangan jurnal elektronik merupakan evolusi dari e-book, di mana setelah ditemukannya teknologi internet dan website pada tahun 1990-an memungkinkan integrasi 
database bibliografi, pengumpulan dan review dokumen dapat dilakukan secara elektronik (Ashikuzzaman, 2018). Jurnal elektronik merupakan produk dari pengelolaan jurnal secara elektronik dan tidak memiliki versi cetak (Asrianda, 2017). Jurnal elektronik merupakan versi elekronik/digital dari jurnal cetak yang dikelola secara konvensial (Lukman et al., 2012). Pengelolaan jurnal elektronik didasarkan pada pemeriksaan sesama ilmuwan (peer-review), dan tidak mempermasalahkan apakah jurnal yang diterbitkan memiliki versi cetak atau tidak (Arianto, 2010).

Salah satu pengelola jurnal elektronik adalah OJS. OJS sudah didesain untuk penerbitan jurnal secara elektronik. Melalui OJS, pengelola jurnal dapat melakukan proses editing secara daring dan manajemen pengguna dapat diatur berdasarkan tingkat user-nya. Meskipun tampilannya sederhana, OJS memiliki fitur yang lengkap dan ramah digunakan (user friendly), kompetibel dengan Open Conference System (OCS), Open Monograph Press (OMP), dan Open Harvest System (OHS) yang merupakan produk lain dari PKP (Arief \& Handoko, 2016).

\subsection{Evaluasi Sistem dengan ISO/IEC 25010}

Pada pengujian dan evaluasi sebuah produk perangkat lunak, seseorang perlu mengetahui permasalahan pada objek sistem yang diteliti, mulai dari disain, source code, hingga proses perbaikan ketika pengembangan produk. Salah satu metode yang dapat digunakan untuk mengevaluasi kualitas sebuah perangkat lunak dapat menggunakan ISO/IE 25010. ISO/IE 25010 merupakan standar yang dirilis untuk menggantikan ISO/IE 9126 yang dianggap sudah tidak relevan pada teknologi yang berkembang sekarang, seperti adanya teknologi cloud computing, smartphone, situs pencarian google, aplikasi sosial media dan juga aplikasi ecommerce (ISO 25000, 2011). Pada ISO/IE 25010 memiliki 8 karakteristik untuk mengukur kualitas dari sebuah produk, sebagaimana terlihat pada Gambar 1.

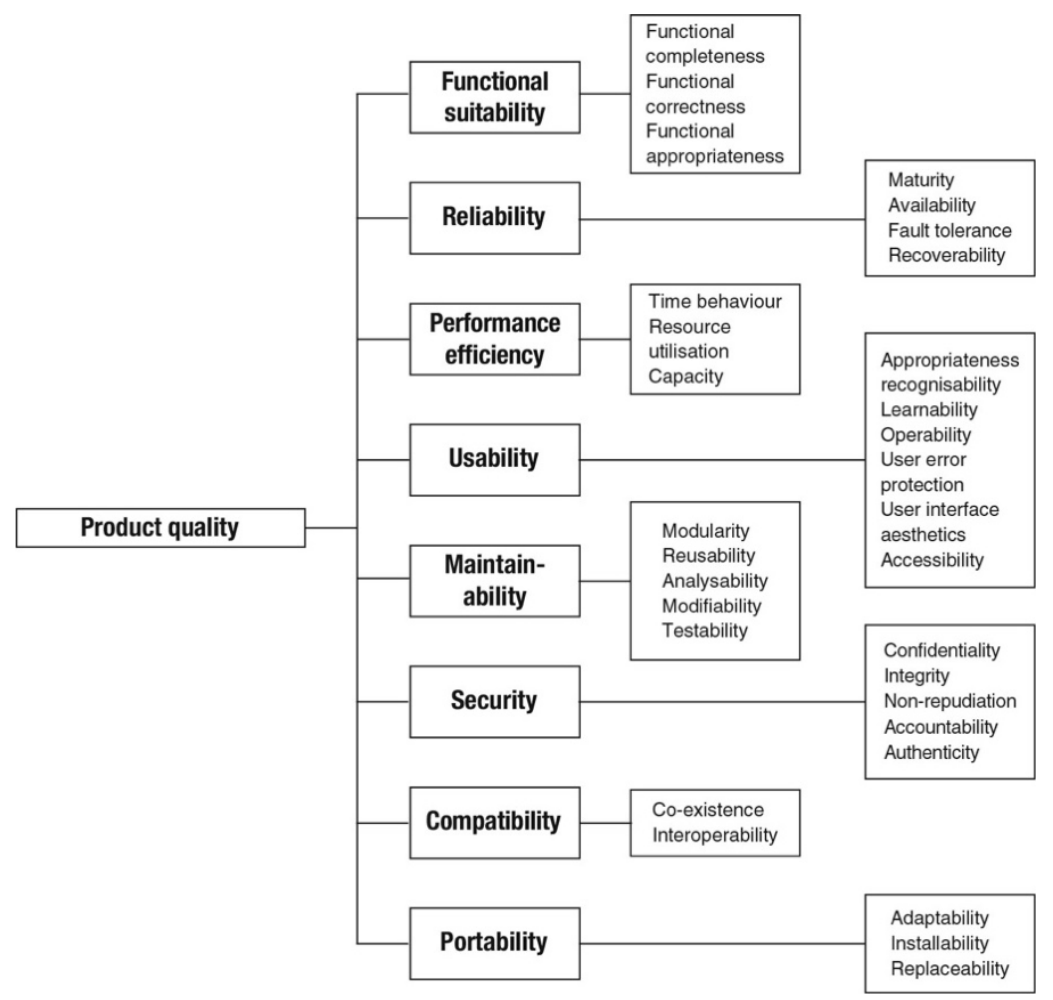

Gambar 1. Product quality model of ISO/IEC 25010 (Wagner, 2013) 
- Functional suitability - pengukuran untuk melihat seberapa baik produk yang dikembangkan dapat menyajikan fungsi untuk memenuhi kebutuhan dalam kondisi tertentu.

- Reliability - pengukuran untuk melihat kualitas produk yang telah dirancang apakah dapat berfungsi pada kondisi dan rentang waktu tertentu.

- Performance Efficiency - pengukuran kinerja penggunaan sumber daya dalam waktu tertentu.

- Usability - pengukuran untuk melihat kepuasan/kelayakan pengguna dalam menjalankan produk yang efektif dan efisien.

- Mantainability - pengukuran terhadap aspek perawatan produk yang telah dihasilkan apakah dapat dirawat dengan efektif dan efisien.

- Security - pengukuran terhadap tingkat keamanan dari produk yang telah dihasilkan, sehingga pengguna dapat menjalankan produk tersebut sesuai dengan kapasitas yang dimilikinya.

- Compatibility - pengukuran terhadap kemampuan produk yang telah dihasilkan dalam bertukar informasi atau dijalankan secara bersamaan dengan produk yang sama.

- Portability - pengukuran terhadap kemampuan produk yang telah dihasilkan dalam hal perpindahan dari satu perangkat ke perangkat yang lain atau dari satu lingkungan ke lingkungan yang lain.

\section{METODE}

Objek penelitian ini adalah jurnal elektronik MAARIF yang dikelola oleh MAARIF Institute. Teknik pengumpulan datanya dengan studi literatur, wawancara, observasi, kuesioner, dan pengujian aplikasi. Waktu pengambilan data yaitu Januari - April 2019. Studi literatur digunakan untuk memperkaya teori yang berkaitan dengan tema penelitian. Wawancara dan observasi digunakan untuk mengumpulkan data yang berkaitan dengan Jurnal MAARIF dan MAARIF Institute. Kuesioner digunakan untuk menguji karakteristik usability dan functional suitability. Software yang digunakan untuk menguji karakteristik performance efficiency dan security.

Pada pengujian karakteristik usability menggunakan kuesioner USE yang diadaptasi dari alat ukur measuring usability with the USE questionnaire (Lund, 2001). Jumlah responden sebanyak 105 responden, yang terdiri dari tim redaksi dan pengguna sistem Jurnal MAARIF. Kuesioner pada pengujian usability terdiri dari 30 pernyataan dengan menggunakan Skala Likert. Uji validitas dan reliabilitas data menggunakan Alpha Cronbach dan SPSS versi 16, dengan kriteria factor loading $>0,3$ untuk validitas, dan $>$ dari 0,7 untuk reliabilitas.

Pada pengujian functional suitability menggunakan instrumen cheklist yang harus ada pada sistem jurnal elektronik sesuai dengan pembagian user. Pengujian ini melibatkan responden yang terdiri dari kalangan praktisi website dan pengelola jurnal. Pengolahan data pada pengujian ini menggunakan Skala Guttman, untuk memperoleh respon yang tegas ("YA" atau "TIDAK") dari responden (Sugiyono, 2016). Hasil pengujian kemudian diolah menggunakan perhitungan/matriks kelengkapan fitur (Feature Completeness) - untuk mengukur fungsi-fungsi yang ada pada produk setelah dioperasionalkan (Acharya \& Sinha, 2013). Pengujian karakteristik performance efficiency menggunakan GTMetrix berdasarkan aturan Yslow dan PageSpeed. Pengujian karakteristik security menggunakan aplikasi Acunetix Web Vulnerability Scanner 10,5. 


\section{HASIL DAN PEMBAHASAN}

\subsection{Hasil Pengujian}

\section{Tahapan Pengujian Karakteristik Usability}

Berdasarkan hasil pengolahan data reliabilitas diperoleh nilai 0,931 , variabel sangat reliable dan mampu mengukur objek yang diukur. Hasil pengujian dapat dilihat pada Tabel 1.

\section{Tabel 1. Hasil Pengujian Reliability dengan Cronbach's Alpha}

\begin{tabular}{|c|c|c|}
\hline $\begin{array}{c}\text { Cronbach's } \\
\text { Alpha }\end{array}$ & $\begin{array}{c}\text { Cronbach's Alpha Based } \\
\text { on Standardized Items }\end{array}$ & $\begin{array}{c}\text { N of } \\
\text { Items }\end{array}$ \\
\hline 440.931 & 0,931 & 30 \\
\hline
\end{tabular}

Sementara hasil uji validitas instrumen menyatakan bahwa dari 30 item pertanyaan terdapat 2 item yang gugur (butir item 25 dan 29) dan sisanya dinyatakan valid. Dua item yang dinyatakan gugur karena tidak memenuhi syarat validitas item yang harus berada pada skor minimal 0,3 menurut standar Cronbach's. Nilai terendah adalah 0,274 dan nilai tertinggi sebanyak 0,733. Hal tersebut dapat dilihat pada Tabel 2.

Tabel 2. Hasil Pengujian Validitas Menggunakan SPSS Versi 16

\begin{tabular}{|c|c|c|c|c|}
\hline \multicolumn{5}{|c|}{ Item-Total Statistics } \\
\hline $\begin{array}{c}\text { Item } \\
\text { Pengujian }\end{array}$ & $\begin{array}{c}\text { Scale Mean } \\
\text { if Item } \\
\text { Deleted }\end{array}$ & $\begin{array}{c}\text { Scale } \\
\text { Variance if } \\
\text { Item Deleted }\end{array}$ & $\begin{array}{c}\text { Corrected } \\
\text { Item-Total } \\
\text { Correlation }\end{array}$ & $\begin{array}{c}\text { Cronbach's } \\
\text { Alpha if Item } \\
\text { Deleted }\end{array}$ \\
\hline v1 & 118,6667 & 127,686 & 0,409 & 0,930 \\
\hline v2 & 118,9238 & 126,033 & 0,480 & 0,929 \\
\hline v3 & 118,4286 & 128,016 & 0,455 & 0,930 \\
\hline v4 & 119,2381 & 124,760 & 0,490 & 0,930 \\
\hline v5 & 118,6476 & 128,057 & 0,480 & 0,929 \\
\hline v6 & 118,6286 & 126,005 & 0,612 & 0,928 \\
\hline v7 & 118,6476 & 129,038 & 0,405 & 0,930 \\
\hline v8 & 118,7810 & 127,653 & 0,473 & 0,929 \\
\hline v9 & 118,7429 & 124,481 & 0,663 & 0,927 \\
\hline v10 & 118,8762 & 124,840 & 0,569 & 0,928 \\
\hline v11 & 118,8190 & 124,150 & 0,671 & 0,927 \\
\hline v12 & 118,9429 & 125,151 & 0,556 & 0,928 \\
\hline v13 & 118,8952 & 124,306 & 0,641 & 0,927 \\
\hline v14 & 118,9143 & 123,425 & 0,612 & 0,928 \\
\hline v15 & 118,9810 & 125,865 & 0,560 & 0,928 \\
\hline v16 & 119,1333 & 122,963 & 0,575 & 0,928 \\
\hline v17 & 118,4952 & 128,887 & 0,408 & 0,930 \\
\hline v18 & 118,8095 & 127,310 & 0,564 & 0,928 \\
\hline v19 & 118,8190 & 126,592 & 0,610 & 0,928 \\
\hline v20 & 118,8571 & 123,431 & 0,733 & 0,926 \\
\hline v21 & 118,8857 & 127,448 & 0,583 & 0,928 \\
\hline
\end{tabular}




\begin{tabular}{|c|c|c|c|c|}
\hline $\mathrm{v} 22$ & 118,7333 & 126,255 & 0,549 & 0,928 \\
\hline $\mathrm{v} 23$ & 119,0190 & 122,519 & 0,692 & 0,926 \\
\hline $\mathrm{v} 24$ & 118,7333 & 124,909 & 0,660 & 0,927 \\
\hline $\mathrm{v} 25$ & 118,4571 & 130,731 & 0,277 & 0,931 \\
\hline $\mathrm{v} 26$ & 119,0000 & 125,865 & 0,576 & 0,928 \\
\hline $\mathrm{v} 27$ & 118,7905 & 128,071 & 0,448 & 0,930 \\
\hline $\mathrm{v} 28$ & 118,9810 & 124,942 & 0,609 & 0,928 \\
\hline $\mathrm{v} 29$ & 118,6571 & 130,439 & 0,274 & 0,932 \\
\hline $\mathrm{v} 30$ & 118,7333 & 128,044 & 0,506 & 0,929 \\
\hline
\end{tabular}

Adapun hasil pengolahan datanya dapat dilihat pada Gambar 2.

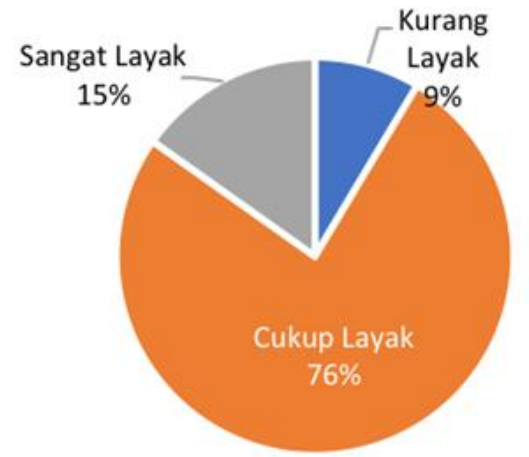

Gambar 2. Grafik hasil pengujian karakteristik usability pada 105 responden

Gambar 2 menunjukan bahwa sebanyak 76\% responden menilai bahwa sistem jurnal elektonik MAARIF cukup layak untuk digunakan, $15 \%$ responden menilai jurnal elektronik MAARIF sangat layak untuk digunakan, sementara 9\% responden menilai kurang layak. Dilihat dari 4 dimensi pada item pertanyaan, yaitu kegunaan (usefulness), kemudahan penggunaan (ease of use), kemudahan mempelajari (ease of learning), dan kepuasan pengguna (satisfaction), hasil perhitungannya terlihat pada Tabel 3 .

Tabel 3. Hasil Pengolahan Data pada 4 Dimensi

\begin{tabular}{|c|c|c|c|c|}
\hline \multirow{2}{*}{ Nilai } & \multicolumn{4}{|c|}{ Dimensi } \\
\cline { 2 - 5 } & $\begin{array}{c}\text { Kegunaan/ } \\
\text { Usefulness } \\
(\%)\end{array}$ & $\begin{array}{c}\text { Kemudahan } \\
\text { Penggunaan /Ease } \\
\text { of Use (\%) }\end{array}$ & $\begin{array}{c}\text { Kemudahan } \\
\text { Mempelajari/ } \\
\text { Ease of Learning (\%) }\end{array}$ & $\begin{array}{c}\text { Kepuasan/ } \\
\text { Satisfactio } \\
\mathrm{n}(\%)\end{array}$ \\
\hline Rendah & 9 & 13 & 13 & 25 \\
\hline Sedang & 75 & 70 & 68 & 58 \\
\hline Tinggi & 16 & 17 & 19 & 17 \\
\hline
\end{tabular}

\section{Tahapan Pengujian Karakteristik Functional Suitability}

Pengujian karakteristik functional suitability diujikan pada 1 orang ahli dalam pengembangan website dan 5 orang dari pengelola Jurnal MAARIF. Hasil pengujian karakteristik functional suitability terlihat pada Tabel 4. 
Tabel 4. Hasil Pengujian Karakteristik Functional Suitability

\begin{tabular}{|c|l|c|c|}
\hline No & \multicolumn{1}{|c|}{ Pertanyaan } & Jawaban \\
\cline { 2 - 4 } 1 & $\begin{array}{l}\text { Fungsi login untuk masuk ke halaman dashboard sudah berjalan } \\
\text { dengan baik. }\end{array}$ & 6 & 0 \\
\hline 2 & $\begin{array}{l}\text { Fungsi logout untuk masuk ke halaman dashboard sudah berjalan } \\
\text { dengan baik. }\end{array}$ & 6 & 0 \\
\hline 3 & $\begin{array}{l}\text { Fungsi register untuk menjadi pengguna sistem sudah berjalan dengan } \\
\text { baik. }\end{array}$ & 5 & 1 \\
\hline 4 & $\begin{array}{l}\text { Fungsi untuk menambah, menampilkan, mengubah, menghapus serta } \\
\text { mengedit user sudah berjalan dengan baik. }\end{array}$ & 6 & 0 \\
\hline 5 & $\begin{array}{l}\text { Fungsi menu submission untuk menampilkan dan mengelola naskah } \\
\text { yang masuk sudah berjalan dengan baik. }\end{array}$ & 6 & 0 \\
\hline 6 & $\begin{array}{l}\text { Fungsi editor yang bertanggung jawab terhadap keseluruhan proses } \\
\text { review, memantau artikel yang masuk dan kemudian menunjuk } \\
\text { reviewer, serta publikasi jurnal sudah berjalan dengan baik. }\end{array}$ & 6 & 0 \\
\hline 7 & $\begin{array}{l}\text { Fungsi mitra bestari yang bertugas memeriksa keabsahan dan kualitas } \\
\text { isi artikel berdasarkan pada kebijakan dan aturan yang telah ditetapkan } \\
\text { sudah berjalan dengan baik. }\end{array}$ & 6 & 0 \\
\hline 8 & $\begin{array}{l}\text { Fungsi copy editor yang bertanggung jawab terhadap keabsahan tata } \\
\text { bahasa, kesesuaian dengan format jurnal, gaya penulisan, serta } \\
\text { bibliografi dan rujukan sudah berjalan dengan baik. }\end{array}$ & 6 & 0 \\
\hline 9 & $\begin{array}{l}\text { Fungsi layout editor yang bertanggung jawab terhadap pengaturan } \\
\text { tampilan jurnal yang akan diterbitkan, seperti tata letak, pengaturan } \\
\text { format gambar, serta konversi format artikel sudah berjalan dengan } \\
\text { baik. }\end{array}$ & 6 & 0 \\
\hline 10 & $\begin{array}{l}\text { Fungsi proofreader yang bertanggung jawab untuk memeriksa } \\
\text { keabsahan penulisan, tipografi, dan tanda baca sudah berjalan dengan } \\
\text { baik. }\end{array}$ & 6 & 0 \\
\hline 11 & $\begin{array}{l}\text { Fungsi pembaca (reader) untuk dapat menikmati penggunaan sistem } \\
\text { Jurnal MAARIF sudah berjalan dengan baik. }\end{array}$ & 6 & 0 \\
\hline 12 & $\begin{array}{l}\text { Fungsi penulis (author) untuk mengirimkan artikel melalui proses } \\
\text { unggah dokumen, serta melacak sampai dimana proses penerbitan } \\
\text { artikelnya sudah berjalan dengan baik. }\end{array}$ & 6 & 0 \\
\hline & \multicolumn{1}{|c|}{ Total } \\
\hline
\end{tabular}

Tabel 4 menunjukkan bahwa dari 12 item pertanyaan terdapat 71 jawaban "Ya" dan 1 jawaban "Tidak" dari responden. Pengukuran pada pengujian karakteristik functional suitability menggunakan rumus:

$$
X=\frac{I}{P}
$$

\section{Keterangan:}

$I=$ banyaknya fungsi/fitur yang berhasil dijalankan

$P=$ banyaknya fungsi/fitur yang dirancang 
Perhitungan karakteristik fungtional suitability adalah sebagai berikut:

$I: 12 \times$ jumlah penguji $=12 \times 6=71$

$P: 12 \times$ Jumlah penguji $=12 \times 6=72$

Sehingga:

$$
X=\frac{71}{72}=0,9
$$

Berdasarkan pengolahan melalui rumus di atas, sistem pengelolan Jurnal MAARIF dinyatakan baik dalam karakterisitik functional suitability. Karena nilai $X=0,9$ yang berarti bahwa nilai mendekati 1 - yang terlihat dari banyaknya fitur yang berhasil dijalankan.

\section{Pengujian Karakteristik Performance Efficiency}

Berdasarkan hasil pengujian karakteristik performance efficiency dengan $Y$ slow dan PageSpeed diperoleh nilai rata-rata dari fitur yang diuji (Tabel 5).

Tabel 5. Hasil Pengujian Performance Efficiency

\begin{tabular}{|c|l|c|c|c|c|}
\hline No & \multicolumn{1}{|c|}{ Halaman web } & $\begin{array}{c}\text { PageSpeed } \\
\text { Grade }\end{array}$ & $\begin{array}{c}\text { Yslow } \\
\text { Grade }\end{array}$ & $\begin{array}{c}\text { Page Load } \\
(\text { detik })\end{array}$ & $\begin{array}{c}\text { Page Size } \\
(\mathrm{Kb})\end{array}$ \\
\hline 1 & Home & C (74\%) & A $(93 \%)$ & 3,4 & 763 \\
\hline 2 & Login & C (74\%) & B (88\%) & 2,7 & 653 \\
\hline 3 & Register & C (74\%) & B (88\%) & 2,5 & 657 \\
\hline 4 & Archive & C (74\%) & B (88\%) & 4,7 & 693 \\
\hline 5 & About & C (74\%) & B (88\%) & 3,6 & 654 \\
\hline 6 & Writing Guide & C (74\%) & B (88\%) & 3,4 & 654 \\
\hline 7 & Publication Ethics & C (74\%) & B (88\%) & 6,1 & 656 \\
\hline 8 & Search & C (74\%) & B (88\%) & 3,3 & 654 \\
\hline \multicolumn{2}{|c|}{ Rata-rata } & C (74\%) & B (88,5\%) & 3,7 & 673 \\
\hline
\end{tabular}

Tabel 5 menunjukkan bahwa rata-rata skor kualitas untuk karakteristik performance efficiency dengan pengukuran PageSpeed berada pada Grade C (74\%) yang berarti sedang. Pengukuran dengan Yslow pada Grade B (88\%), yang berarti baik. Page load 3,7 detik pengalaman dan page size $673 \mathrm{~kb}$ per-halaman.

\section{Pengujian Karakteristik Security}

Pengujian karakteristik security menggunakan aplikasi Acunetix Web Vulnerability Scanner 10,5, dan hasil pengujiannya terlihat pada Gambar 3. 


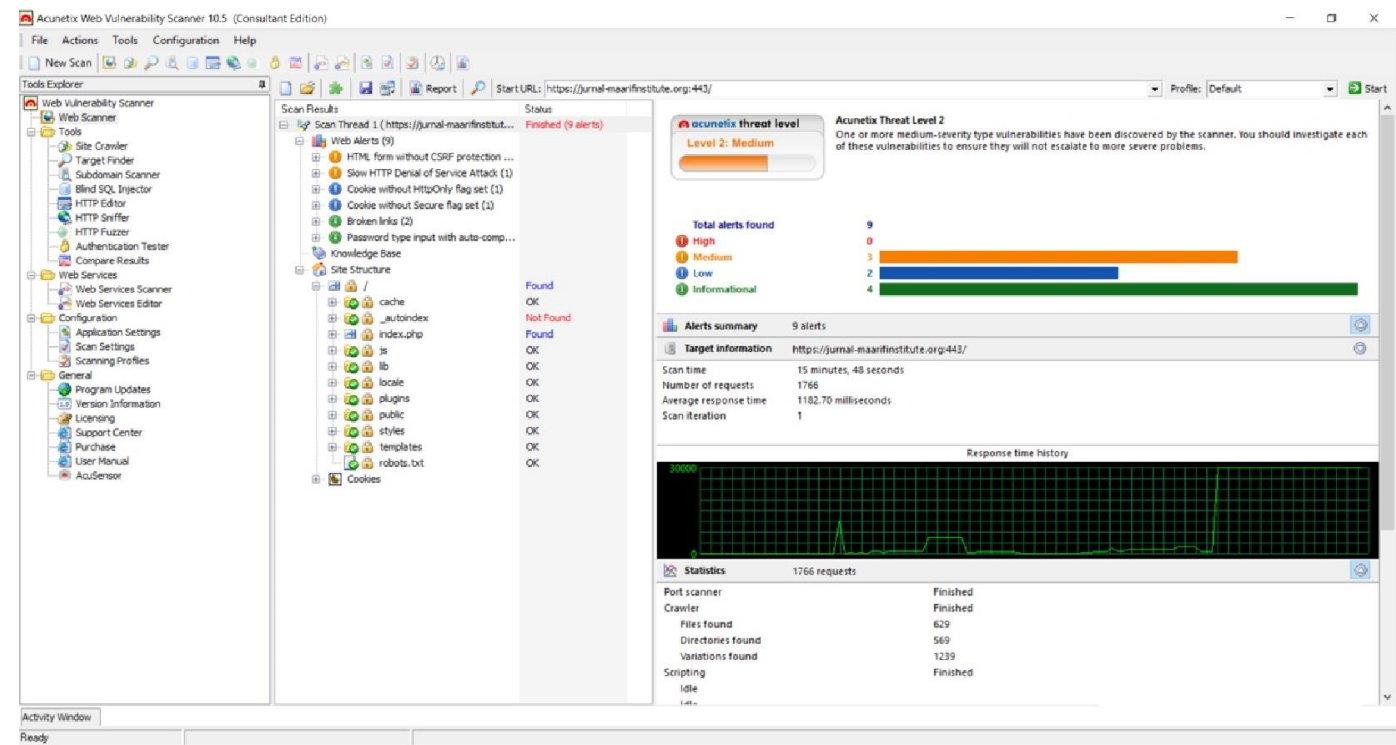

Gambar 3. Hasil pengujian dengan aplikasi Acunetix Web Vulnerability Scanner 10.5

Gambar 3 menunjukkan bahwa sistem pengelolaan jurnal elektronik MAARIF memiliki tingkat keamanan level 2. Hal tersebut mengindikasikan adanya kesalahan pada konfigurasi server dan kekurangan peng-kodean pada web sehingga terjadi gangguan pada server jurnal.

\subsection{Pembahasan}

Melalui tahapan pengujian pada empat karakteristik di atas, terlihat bahwa karakteristik usability (4 dimensi yang ada pada item pertanyaan) khususnya dimensi kegunaan memiliki nilai dengan skala sedang (cukup) yang bersumber dari jawaban $75 \%$ responden. Hal lain yang perlu diperhatikan adalah $25 \%$ responden yang masih merasa rendah/kurang pada dimensi kepuasan ketika menggunakan sistem Jurnal MAARIF - sehingga perlu dievaluasi lebih lanjut.

Pada tahapan pengujian karakteristik functional sutability Jurnal MAARIF, yang memiliki kualitas tinggi dan memenuhi aspek functional suitability menunjukkan adanya keberhasilan pengujian (mencapai $99 \%$ atau memiliki nilai $X=0,9$ ). Pada pengujian karakteristik performance efficiency, Jurnal MAARIF dianggap telah memenuhi karakteristik tersebut, karena rata-rata waktu yang dibutuhkan untuk memuat halaman selama 3,7 detik. Waktu tersebut kurang dari 10 detik sebagaimana yang dikatakan oleh Nielsen (2010), dan sudah sesuai dengan standar Aptimize (2010). Pada tahapan pengujian karakteristik security, Jurnal MAARIF dianggap telah memiliki level keamanan medium - sehingga perlu ditingkatkan level keamanannya.

\section{KESIMPULAN}

Berdasarkan hasil pengujian dan pembahasan di atas dapat disimpulkan bahwa Jurnal MAARIF layak untuk digunakan, terutama pada aspek penggunaan (usability) dengan $76 \%$ responden. Pada karakteristik functional suitability, sistem jurnal telah memenuhi standar karena fungsi utama dari sistem yang dibangun berjalan $99 \%$ karena memiliki nilai $\mathrm{X}$ mendekati 1 yaitu 0,9. Pada pengujian karakteristik performance efficiency telah memenuhi standar ISO/IEC 25010, karena rata-rata 
waktu yang dibutuhkan untuk memuat halaman selama 3,7 detik, sedangkan untuk karakteristik security masih pada level 2 (medium).

Hasil penelitian ini diharapkan dapat menjadi bahan masukan untuk perbaikan sistem Jurnal MAARIF, seperti: (1) mengadakan pelatihan penggunaan sistem jurnal elekronik bagi pengelola jurnal, dan menyediakan panduan penggunaan jurnal elektronik MAARIF bagi pengguna; (2) meningkatkan kapasitas server jurnal, misalnya hosting server jenis VPS (Virtual Private System) - untuk meningkatkan kecepatan akses dan level keamanan sistem jurnal. Hasil penelitian ini juga diharapkan dapat menjadi acuan pengembangan jurnal elektronik MAARIF Institute menuju persiapan akreditasi nasional.

\section{UCAPAN TERIMAKASIH}

Ucapan terima kasih disampaikan kepada seluruh pihak yang telah terlibat dalam proses penelitian ini, terutama kepada pihak redaksi Jurnal MAARIF yang telah bersedia menjadi responden penelitian. 


\section{DAFTAR PUSTAKA}

Acharya, A. \& Sinha, D. 2013. Assessing the Quality of M-Learning Systems using ISO / IEC 25010, International Journal of Advanced Computer Research, 3, pp. 67-75.

Arianto, M. S. 2010. Membangun Database E-Journal (Penguatan Local Content dan Peningkatan Akses Jurnal-Jurnal Kampus. Al-Maktabah, 10, 163-81.

Arief, I. \& Handoko, H. 2016. Jurnal Online Dengan Open Journal System. Padang: LPTIK Universitas Andalas.

Ashikuzzaman, M. 2018. About Electronic Journal (E-Journal). http://www.lisbdnet.com/electronic-journal-e-journal/ (Accessed: 12 February 2020).

Asrianda, A. 2017. Teknik dan Implementasi Pengelolaan Jurnal Online. Ed. Fadlisyah. UNIMAL PRESS.

Hakam, F. 2017. Metode Evaluasi Sistem Informasi. https://www.slideshare.net/FahmiHakam/metode-evaluasi-sistem-informasi (Accessed: 16 February 2020).

Handoko, A.I. \& Yuhefizar, Y. 2015. Kupas Tuntas Open Jurnal System Versi 3. Jakarta: PT Elex Media Komputindo, Kompas Gramedia.

ISO 25000. 2011. ISO/IEC 25010. https://iso25000.com/index.php/en/iso-25000-standards/iso25010 (Accessed: 30 January 2019).

Lukman, L. et al. 2012. Perkembangan Open Access Jurnal Ilmiah Indonesia. https://www.academia.edu/15358584/Perkembangan_Open_Access_Jurnal_Ilmiah_Indonesia. (Accessed: 30 January 2019).

Lukman, L. 2015. Manajemen Pengelolaan Jurnal: Evaluasi Kesiapan Sesuai Akreditasi Nasional. pp. 23-24.

Lund, L. 2001. USE Questionnaire: Usefulness, Satisfaction, and Ease of use, pp. 2-3.

Mirza, A. H. et al. 2019. Evaluasi Sistem Informasi Usaha Kecil dan Menengah (UKM) Evaluation of Small and Medium Business (SMEs) Information, 6(4), pp. 397-406.

Nashihuddin, W. \& Aulianto, D.R. 2015. Evaluasi Kepuasan Pelanggan pada Jasa Perpustakaan dan ISSN PDII-LIPI, BACA: Jurnal Dokumentasi dan Informasi, pp. 77-95.

Prasetyawan, Y. Y. 2017. Perkembangan Open Access dan Kontribusinya bagi Komunikasi Ilmiah di Indonesia, 1(2), pp. 93-100.

Putra. P. 2020. Pengertian Evaluasi: Fungsi, Tujuan, Metode \& Contoh Evaluasi. https://salamadian.com/pengertian-evaluasi/ (Accessed: 15 February 2020).

Sugiyono, S. 2016. Metode Penelitian Kuantitatif Kualitatif dan $R \& D$. Alfabeta.

Tangkudung, I. et al. 2019. Evaluasi Website Menggunakan Metode ISO/IEC 25010, pp. 87-107.

Yuliana, N. 2018. Manajemen Pengelolaan e-Journal (Jurnal Online). https://www.slideshare.net/relawanjurnal/pengelolaan-ejournal-dengan-ojs (Accessed: 15 February 2020). 
